\title{
Defects formation mechanism and evaluation of surface roughness in machining $\mathrm{Al} / \mathrm{SiCp}$ composites
}

\author{
Chunzheng DUAN*, Wei SUN*, Zhan FENG* and Fangyuan ZHANG* \\ * School of Mechanical Engineering, Dalian University of Technology \\ 2 \# Ling Gong Road, Ganjingzi District, Dalian 116024, China \\ E-mail: duancz@dlut.edu.cn
}

Received: 12 October 2017; Accepted: 13 December 2017

\begin{abstract}
During machining $\mathrm{Al} / \mathrm{SiCp}$ composites, the machined surface takes on many defects such as grooves, pits, voids and protuberances, which greatly affect the characterization parameters of surface topography. However, a detailed investigation of the formation mechanism of surface defects in machining $\mathrm{Al} / \mathrm{SiCp}$ composites is still lacking, and few surface roughness evaluation methods have been developed for separating the surface defects from roughness. In this paper, the formation mechanism of surface defects is revealed, and a roughness extraction method based on DT-CWT is established to extract the surface defects from roughness and conduct a roughness evaluation on the machined surface of $\mathrm{Al} / \mathrm{SiCp}$ composites. Compared with the least-square method and Gaussian filter, the roughness extraction method based on DT-CWT has higher stability and can effectively distinguish between surface roughness and surface defects. According to the surface roughness evaluation based on the roughness extraction method, it is found that the surface roughness value of $2024 \mathrm{Al} / \mathrm{SiCp}$ composite is lower compared to $6063 \mathrm{Al} / \mathrm{SiCp}$ composite.
\end{abstract}

Keywords : $\mathrm{Al} / \mathrm{SiCp}$ composites, Surface roughness, Cutting force, Fractal dimension, Dual tree complex wavelet transform

\section{Introduction}

A metal matrix composite is composite material with at least two constituent parts, one being a metal matrix, the other material may be a different metal or another material, such as a ceramic or organic compound. Among metal matrix composites (MMCs), an Al-matrix composite reinforced with silicon carbide particle ( $\mathrm{Al} / \mathrm{SiCp}$ ) is composite material with aluminum or aluminum alloy as matrix and $\mathrm{SiC}$ particles as reinforcement, which offers lighter weight, greater specific strength and wear resistance than those conventional monolithic metals (Davim, 1990; Pramanik et al., 2008). Therefore, $\mathrm{Al} / \mathrm{SiCp}$ composites have potential to replace conventional materials in various fields of application such as advanced weapons systems, automotive, aeronautical and aerospace systems (Rohatgi, 1991; Rawal, 2001). However, one factor that prevents $\mathrm{Al} / \mathrm{SiCp}$ composites from being widely used is the difficulty of machining these materials. Machining $\mathrm{Al} / \mathrm{SiCp}$ composites is very difficult owing to it's heterogeneity and the fact that reinforcements are extremely abrasive, which results in producing large numbers of defects on the machined surface (Kunze and Bampton, 2001).

In recent years, numerous reports can be found in the literatures describing the machined surface quality of $\mathrm{Al} / \mathrm{SiCp}$ composites. Palanikumar and Karthikeyan (Palanikumar and Karthikeyan, 1998) made an attempt to assess the factors influencing surface roughness on the machining of $\mathrm{Al} / \mathrm{SiCp}$ composites. They found that the feed rate has greater influence on surface roughness than cutting speed and volume fraction of SiC. Dabade et al (Dabade et al.,2007) carried out cutting experiments using CBN inserts with and without wiper on cutting edge to study the integrity of the machined surface on $\mathrm{Al} / \mathrm{SiCp}$ composites. Their microstructural analysis showed that the number of feed marks, pits and cracks on the machined surface is significantly reduced using the wiper inserts. Kannan and Kishawy (Kannan and Kishawy, 2006) investigated the effects of cutting parameters and particulate properties on the microhardness variation of the aluminium matrix beneath the machined surface. Their metallographic analysis revealed severely damaged machined subsurface 
with numerous geometrical defects and plastically deformed aluminium matrix. As a matter of fact, a lot of defects such as protuberances, voids and grooves appear on the machined surface of Al/SiCp composites. El-Gallab and Sklad (ElGallab and Sklad, 1998) analyzed the machined surfaces of $\mathrm{Al} / 20 \% \mathrm{SiC}$ composites using scanning electron microscopic (SEM). They found that some of the reinforcing SiC particles become pulled-out of the surface, whilst others become fractured. Moreover, the voids and cracks initiate around the particles due to the plastic deformation of matrix material. To investigate the surface quality, Ge et al (Ge et al., 2008) conducted a series of ultra-precision turning experiments on 2024Al/SiCp and ZL101A/SiCp composites. They reported that the machined surface of Al/SiCp composites take on many defects such as pits, voids, microcracks, grooves, protuberances, matrix tearing and so on. It is clear from above literatures that most of the defects studied in machining $\mathrm{Al} / \mathrm{SiCp}$ composites concentrate on the defect types appearing on the machined surface. However, a detailed investigation of the formation mechanism of surface defects in machining $\mathrm{Al} / \mathrm{SiCp}$ composites is still lacking. Besides, revealing formation mechanism of surface defects is important for optimizing the quality of machined surface.

To study the effect of defects on characterization of machined surface, a few evaluation methods have been developed for extracting information of 3D surface topography. Zhou and Zhao (Zhou and Zhao, 2011) established a 3D evaluation method of cutting surface topography for $\mathrm{C} / \mathrm{Ph}$ composites. Through the result of $3 \mathrm{D}$ roughness evaluating for $\mathrm{C} / \mathrm{Ph}$ composites, the characteristics of the surface topography in $\mathrm{C} / \mathrm{Ph}$ composites can be comprehensively and authentically evaluated by the $3 \mathrm{D}$ evaluation method. However, the method resulting in distortion of the surface defects is unable to extract surface information stably. Wang et al (Wang et al., 2011) constructed the reference plane for 3D machined surface roughness of $\mathrm{Al} / \mathrm{SiCp}$ composites with least square fitting method and Gaussian filter method. They reported that the least squares method is most suitable for processing the originally machined surface of $\mathrm{Al} / \mathrm{SiCp}$ composites because of its good accordance to the original surface's characteristics. However, this method for constructing the machined surface is based on the measured plane, which restricts its application. Up to now, previous investigations for extracting machined surface information of $\mathrm{Al} / \mathrm{SiCp}$ composites are still few. Moreover, in the evaluation of surface quality, the defect information is always included in the roughness surface, and the roughness information and the defect information cannot be effectively distinguished.

In fact, many surface defects seriously affect the quality evaluation of the machined surface. The protuberances have significant effect on functional surface in the running in period, decreasing the workpiece fit (Zhang et al., 2013). The stress concentration caused by the voids and grooves results in the reduction of coating adhesion and local wear (Qiu et al., 2012; Qiu et al., 2013). However, the wear process of the workpiece is mainly affected by surface roughness (Svahn et al., 2003). Therefore, describing the surface roughness and defects of the particles reinforced composites separately can evaluate the quality of machined surface more effectively. The purpose of this paper is to investigate the formation mechanism of surface defects and the surface quality evaluation in machining $\mathrm{Al} / \mathrm{SiCp}$ composites. A roughness extraction method based on Dual-tree Complex Wavelet Transform (DT-CWT) is explored for separating the surface defects from the surface roughness to provide an insight for understanding the effects of defects on machined surfaced characterization. And the roughness extraction method is adopted to evaluate the surface roughness of $\mathrm{Al} / \mathrm{SiCp}$ composites.

\section{Experimental procedures}

2024Al/SiCp composites and 6063Al/SiCp composites were machined orthogonally under different cutting speeds, in an attempt to analyze the formation mechanism of surface defects and evaluate the surface roughness in machining $\mathrm{Al} / \mathrm{SiCp}$ composites. The cutting of the composites was performed at different cutting speeds ranging from $20 \mathrm{~m} / \mathrm{min}$ to $120 \mathrm{~m} / \mathrm{min}$, and the feed rate is $0.1 \mathrm{~mm} / \mathrm{rev}$. The $\mathrm{Al} / \mathrm{SiCp}$ composites used are listed in Table 1 . The scope of this investigation is limited to orthogonal cutting using the CA6140 lathe. The cutting tool used is polycrystalline diamond (PCD) with $0^{\circ}$ rake angle and $7^{\circ}$ relief angle. The surface integrity of the machined surface was examined by the scanning electron microscope (SEM). Three-dimensional surface topography was measured using ZYGO surface profiler. The sampling range and space in measurement parameters of the workpiece are $68 \mu \mathrm{m} \times 768 \mu \mathrm{m}$ and $3 \mu \mathrm{m}$. The chemical composition and some mechanical properties of metal matrix are listed in Tables 2 and 3 . The physical and mechanical properties of 2024Al and 6063 Al are significant differences. With higher amounts of alloying elements like $\mathrm{Cu}, \mathrm{Mg}$ and $\mathrm{Zn}$ in the 2024Al matrix, it is conducive to forming better mechanical properties. Such a large amount of those alloying elements in 2024Al compared to 6063Al leads to higher yield strength and shear strength and makes the matrix harder. 
Also, 2024Al can still maintain good mechanical properties at high temperatures (Charpentier et al., 2011).

Table 1 Material parameters of $\mathrm{Al} / \mathrm{SiCp}$ composites

\begin{tabular}{c|c|c|c}
\hline \hline $\begin{array}{c}\text { Reinforced } \\
\text { particle }\end{array}$ & $\begin{array}{c}\text { Particulate volume } \\
\text { fraction }[\%]\end{array}$ & $\begin{array}{c}\text { Average particle } \\
\text { size }[\mu \mathrm{m}]\end{array}$ & Aluminum matrix \\
\hline $\mathrm{SiC}$ & 50 & 15,30 & $2024 \mathrm{Al}, 6063 \mathrm{Al}$ \\
\hline
\end{tabular}

Table 2 Chemical composition of metal matrix

\begin{tabular}{c|c|c|c|c|c}
\hline \hline Material & $\mathrm{Cu}[\%]$ & $\mathrm{Si}[\%]$ & $\mathrm{Mg}[\%]$ & $\mathrm{Zn} \mathrm{[ \% ]}$ & $\mathrm{Ti}[\%]$ \\
\hline $2024 \mathrm{Al}$ & $3.8-4.9$ & 0.5 & $1.2-1.8$ & 0.25 & 0.15 \\
$6063 \mathrm{Al}$ & 0.1 & $0.2-0.6$ & $0.45-0.9$ & 0.10 & 0.10 \\
\hline
\end{tabular}

Table 3 Mechanical properties of metal matrix

\begin{tabular}{c|c|c|c|c}
\hline \hline Material & $\begin{array}{c}\text { Tensile strength } \\
{[\mathrm{MPa}]}\end{array}$ & $\begin{array}{c}\text { Yield strength } \\
{[\mathrm{MPa}]}\end{array}$ & $\begin{array}{c}\text { Hardness } \\
{[\mathrm{HBW} 10 / 500]}\end{array}$ & $\begin{array}{c}\text { Shear strength } \\
{[\mathrm{MPa}]}\end{array}$ \\
\hline $2024 \mathrm{Al}$ & 472 & 325 & 120 & 285 \\
$6063 \mathrm{Al}$ & 185 & 145 & 60 & 115 \\
\hline
\end{tabular}

\section{Results and discussions}

\subsection{Formation mechanism of surface defects}

$\mathrm{Al} / \mathrm{SiCp}$ composite is two-phase composite material, which includes hard reinforced particles and soft matrix. In machining $\mathrm{Al} / \mathrm{SiCp}$ composites, the removal mechanism of aluminum matrix is different from that of SiC particles. In fact, the metal matrix and reinforced particles interact with each other during cutting removal of MMCs (Khan, 2012). As shown in Fig. 1 (a), some pulled-out SiC particles are pressed into the aluminum matrix with the pressing effect of the tool secondary flank on the machined surface. As can be seen from Fig.1 (b), the removal mechanism of aluminum matrix is the plastic removal with a certain degree of plastic lateral flow. In addition, partially stripped SiC particles undergo a certain length of tillage in the direction of the cutting speed, forming some plough grooves on the softer aluminum matrix and then being pressed into the aluminum matrix. Ge et al (Ge et al., 2008) showed that three types of grooves can be formed by SiC particles on the machined surface. The first one is the groove with shallow depth, which induced by the crushed or debonded particles. The second one is caused by hard particles which pressed by tool's flank face and embedded into the softer matrix. In this type, the groove created on machined surface is deeper and wider toward the end. The third one is formed by the plucked SiC particle that plowed through the workpiece surface with decreasing plowing depth creating a groove that became narrower and shallower toward the end.

Figure 2 shows the surface defects caused by SiC particles in machining Al/SiCp composites. As shown in Fig. 2 (a), there are pits caused by particle stripping on the machined surface of $\mathrm{Al} / \mathrm{SiCp}$ composites because the $\mathrm{SiC}$ particle's strength is greater than the interface strength when it has little internal defects. The interface failure when the tool is cut into $\mathrm{SiC}$ particles that leads to particles removal from the machined surface and results in the appearance of pits similar to the particle size. In addition, due to the ironing effect of secondary flank face on the surface, there is a certain degree of springback after cutting process, forming micro bump phenomenon on the machined surface. In Fig. 2 (b), there is a big protuberance on the machined surface of $\mathrm{Al} / \mathrm{SiCp}$ composites. The aluminum matrix in the composites is sensitive to temperature, so it is easy to form Built-up Edge (BUE) in machining Al/SiCp composites. The stripped SiC particles and BUE are adhered to the machined surface, forming large protuberances on the machined surface of $\mathrm{Al} / \mathrm{SiCp}$ composites.

The micro voids are formed either due to fine $\mathrm{SiC}$ particles detached from the matrix or due to the rotation of the $\mathrm{SiC}$ particles in order to adapt the deformation of matrix around it, as shown in Fig. 2 (c). Moreover, some SiC particles are squeezed to move in the same direction as cutting speed leading to the phenomenon of particle aggregation. When the network structure formed by particle aggregation is stripped, a large pit can be formed (Wang et al., 2011), as shown in Fig. 3 (b). As can be seen from Fig. 2 (d), the particles are crushed before the interface failure and then pressed by the 
secondary flank into the softer aluminum matrix when the $\mathrm{SiC}$ particles have original defects, resulting in particle crushing on the machined surface of $\mathrm{Al} / \mathrm{SiCp}$ composites.
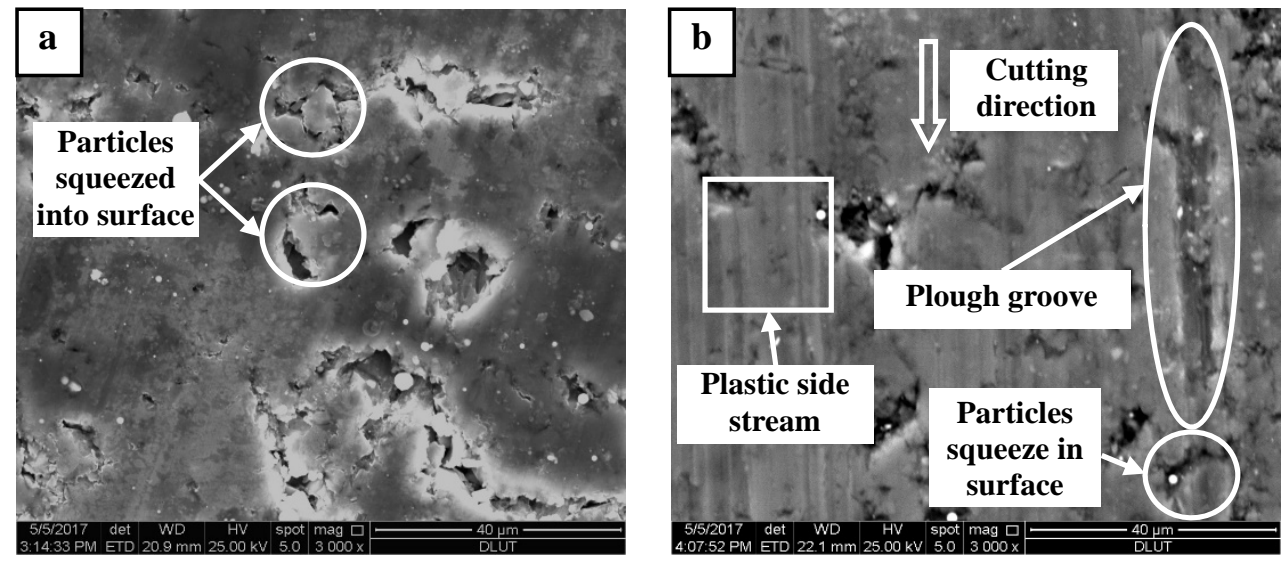

Fig. 1 The surface defects formed by aluminum matrix (2024A1/SiCp- $15 \mu \mathrm{m}$ composite, cutting speed $v=120 \mathrm{~m} / \mathrm{min}$, feed rate $f=0.1 \mathrm{~mm} / \mathrm{rev}$ )
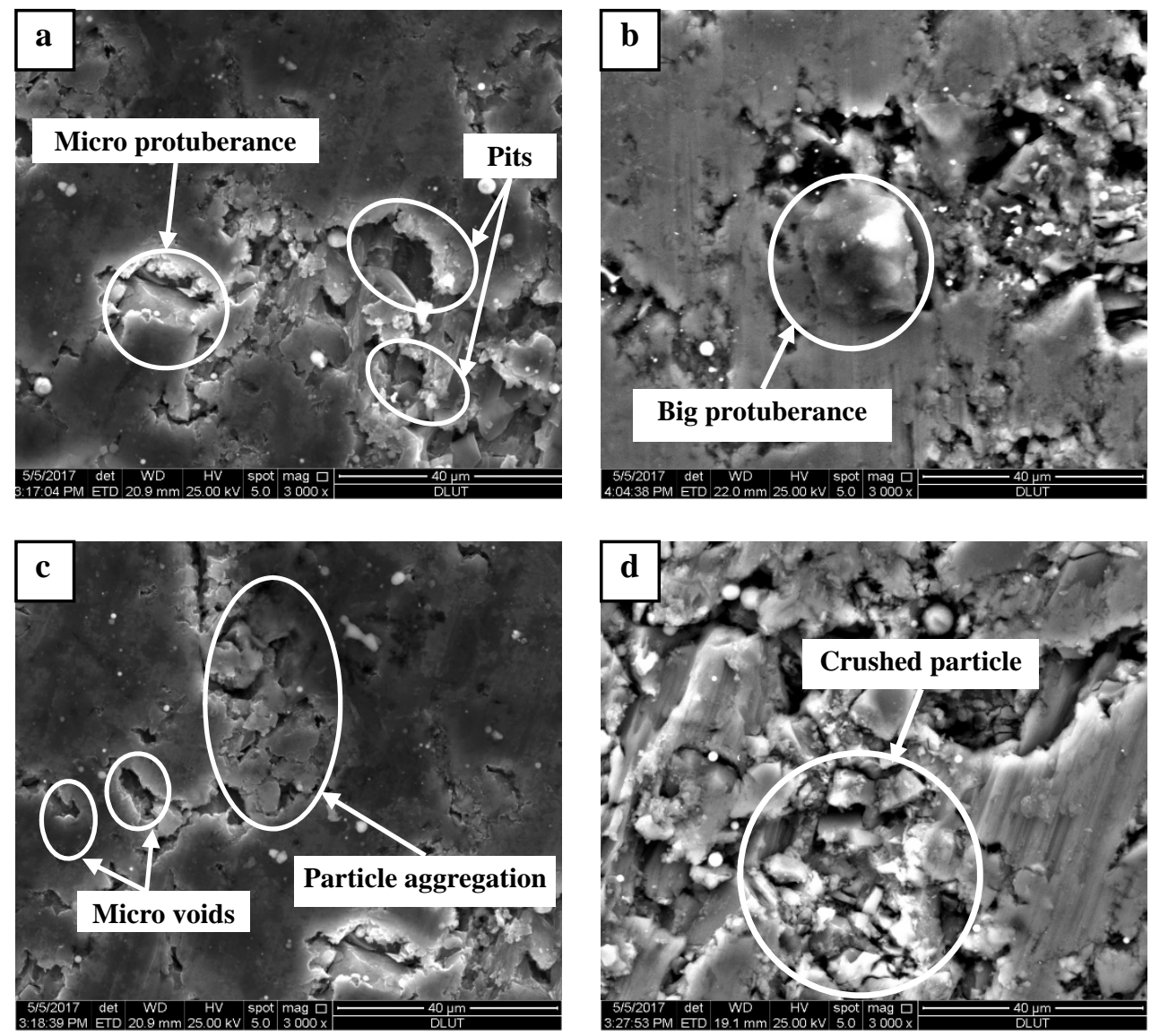

Fig. 2 The surface defects formed by $\mathrm{SiC}$ particles $(2024 \mathrm{Al} / \mathrm{SiCp}-15 \mu \mathrm{m}$ composite, cutting speed $v=120 \mathrm{~m} / \mathrm{min}$, feed rate $f=0.1 \mathrm{~mm} / \mathrm{rev})$

As can be seen from Fig. 3, the microstructure features of machined surfaces are obviously different when $\mathrm{Al} / \mathrm{SiCp}$ composites are machined under various parameters. There is the largest number of defects such as cracked particles, micro voids and large pits on the machined surface when cutting speed is $20 \mathrm{~m} / \mathrm{min}$, as shown in Fig. 3 (b). The hardening of the matrix material with decreasing cutting speed induces the reinforcements to bear greater stress, which cause many particles aggregation and crushing in the $\mathrm{Al} / \mathrm{SiCp}$ composite. The crushed particles can either be pressed in $\mathrm{Al}$ matrix bringing about big bumps or be pulled out of the machined surface causing large pits. The plastic side flow is formed on 
the machined surface of $\mathrm{Al} / \mathrm{SiCp}$ composite because the matrix left behind on the cutting edge is subjected to sufficiently high pressure to cause the soft matrix to flow to the side of cutting edge (Ge et al., 2008). The 6063Al has higher temperature sensitivity than 2024Al, which results in more softening 6063Al matrix leaving behind on the cutting edge when 2024Al/SiCp composite and 6063Al/SiCp composite are machined under the same cutting condition. So, compared with $2024 \mathrm{Al} / \mathrm{SiCp}$ composite, the larger area of plastic side flow induced by the softening matrix appears on the machined surface of $6063 \mathrm{Al} / \mathrm{SiCp}$ composite, as shown in Fig. 3 (a) and (c). As it can be seen from Fig. 3 (a) and (d), the SiC particles are pulled out of the machined surface, which formed numerous pits in the surface. The pits in Fig. 3 (d) are bigger than the pits in Fig. 3 (a) because the size of pits depends on the average particulate size. In the case of machining coarser particles reinforced composites, lots of cracked particles are formed on the machined surface, as shown in Fig. 3 (d). The dislocation density in front of the obstacles increases with the average particulate size, which leads to the dislocation line that requires a larger driving force to glide past the hard particle (Kannan et al., 2009). Thus, the increase in average reinforcing particulate size leads to the increase in the cutting force and makes particles easier to crack.
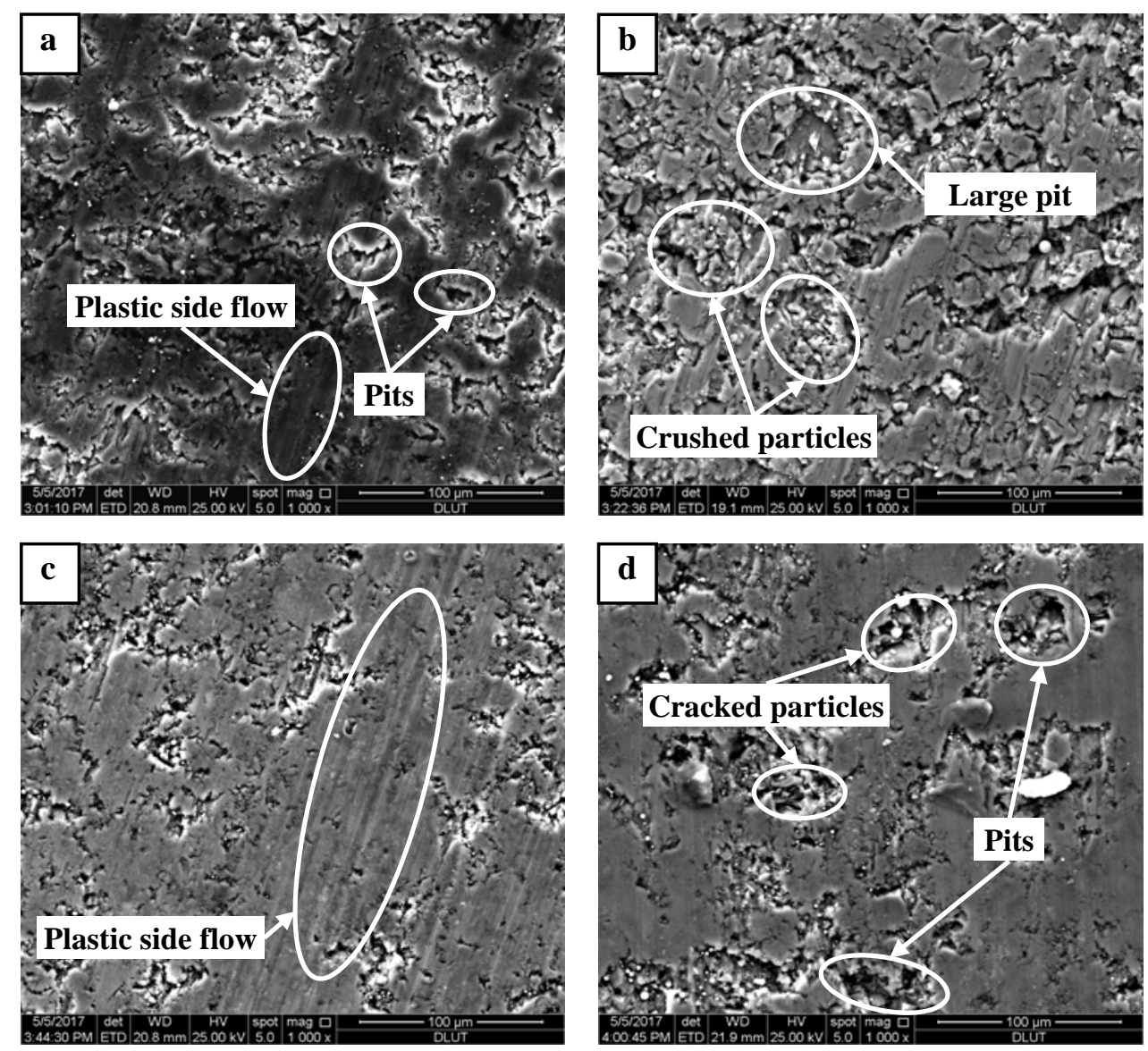

Fig.3 Machined surfaces under different parameters (feed rate $f=0.1 \mathrm{~mm} / \mathrm{rev}$ ). (a) $2024 \mathrm{Al} / \mathrm{SiCp}-15 \mu \mathrm{m}$ composite, cutting speed $v=120 \mathrm{~m} / \mathrm{min}$. (b) $2024 \mathrm{Al} / \mathrm{SiCp}-15 \mu \mathrm{m}$ composite, cutting speed $v=20 \mathrm{~m} / \mathrm{min}$. (c) $6063 \mathrm{Al} / \mathrm{SiCp}-15 \mu \mathrm{m}$ composite, cutting speed $v=120 \mathrm{~m} / \mathrm{min}$. (d) $2024 \mathrm{Al} / \mathrm{SiCp}-30 \mu \mathrm{m}$ composite, cutting speed $v=120 \mathrm{~m} / \mathrm{min}$.

\subsection{Evaluation of surface roughness \\ 3.2.1 Dual-Tree Complex Wavelet Transform}

The Discrete Wavelet Transform (DWT) has an impressive reputation as an image compression tool, but its use for image restoration and enhancement has been hampered by two disadvantages. The one is the lack of shift invariance, which causes major variations in energy distribution. The second one is the poor directional selectivity because its separable filters cannot distinguish between edge features on opposing diagonals (Kingsbury, 2015). The Dual-tree Complex Wavelet Transform (DT-CWT) uses wavelet filters in two trees to obtain real and imaginary parts of complex wavelet coefficients, which can provide an approximate shift invariance, good directionality and selectivity. The two- 
dimensional DT-CWT $\psi^{(c)}(s)$ can be defined as (Kingsbury, 2001):

$$
\psi^{(c)}(s)=\psi_{h}\left(s_{1}\right) \psi_{g}\left(s_{1}\right)-\psi_{g}\left(s_{1}\right) \psi_{g}\left(s_{2}\right)+j\left(\psi_{h}\left(s_{1}\right) \psi_{h}\left(s_{2}\right)+\psi_{g}\left(s_{1}\right) \psi_{g}\left(s_{1}\right)\right)
$$

To overcome some drawbacks of the odd/even filter approach, a $Q$-shift filter is adopted in the DT-CWT. The Q-shift version of the DT-CWT finds a good even-length lowpass filter with a delay of 1/4 sample, which also satisfies the standard orthonormal perfect reconstruction condition of two-band filter banks. The filter satisfies following conditions (Kingsbury, 2000; Jiang and Blunt, 2004):

$$
\left\{\begin{array}{l}
H_{L 2}(z)=H_{L}\left(z^{2}\right)+z^{-1} H_{L}\left(z^{-2}\right), \\
H_{L}(z) H_{L}\left(z^{-1}\right)+H_{L}(-z) H_{L}\left(-z^{-1}\right)=2
\end{array}\right.
$$

where $H_{L 2}(z)$ is a linear-phase lowpass filter of length $4 n$ with half of the desire band width and twice the desired delay; $H_{L}(z)$ is obtained by selecting alternate filter coefficients of $H_{L 2}(z)$.

For two dimensions, the decomposition of the DT-CWT $f(s)$ can be represented by the dilations and translations of a complex scaling function and six complex wavelet functions:

$$
f(s)=\sum_{k \in Z^{2}} a_{J, k} \phi_{J, k}(s)+\sum_{b \in B} \sum_{j \leq J} \sum_{k \in Z^{2}} d_{j, k}^{(b)} \psi_{j, k}^{(b)}(s)
$$

Here, $a_{J, k}$ and $d_{j, k}$ refer to the smooth coefficients at level $J$ and the detail components of coefficients at level $j . s=(s 1, s 2)$ and the $B=\left\{ \pm 15^{\circ}, \pm 45^{\circ}, \pm 75^{\circ}\right\}$ for six sub-bands' directions. The functions of each sub-band can be represented as:

$$
\begin{array}{ll}
\psi^{+15^{\circ}}(s)=\varphi\left(s_{1}\right) \psi\left(s_{2}\right), & \psi^{+45^{\circ}}(s)=\psi\left(s_{1}\right) \psi\left(s_{2}\right), \\
\psi^{+75^{\circ}}(s)=\psi\left(s_{1}\right) \varphi\left(s_{2}\right), & \psi^{-15^{\circ}}(s)=\varphi\left(s_{1}\right) \bar{\psi}\left(s_{2}\right), \\
\psi^{-45^{\circ}}(s)=\psi\left(s_{1}\right) \bar{\psi}\left(s_{2}\right), & \psi^{-75^{\circ}}(s)=\psi\left(s_{1}\right) \bar{\varphi}\left(s_{2}\right)
\end{array}
$$

where $\bar{\varphi}, \bar{\psi}$ is the complex conjugate of $\varphi, \psi$. According to the function shown in the Eq. (4), the twodimensional DT-CWT has six directional selectivity, which improves the retrieval performance of the surface topography characteristics.

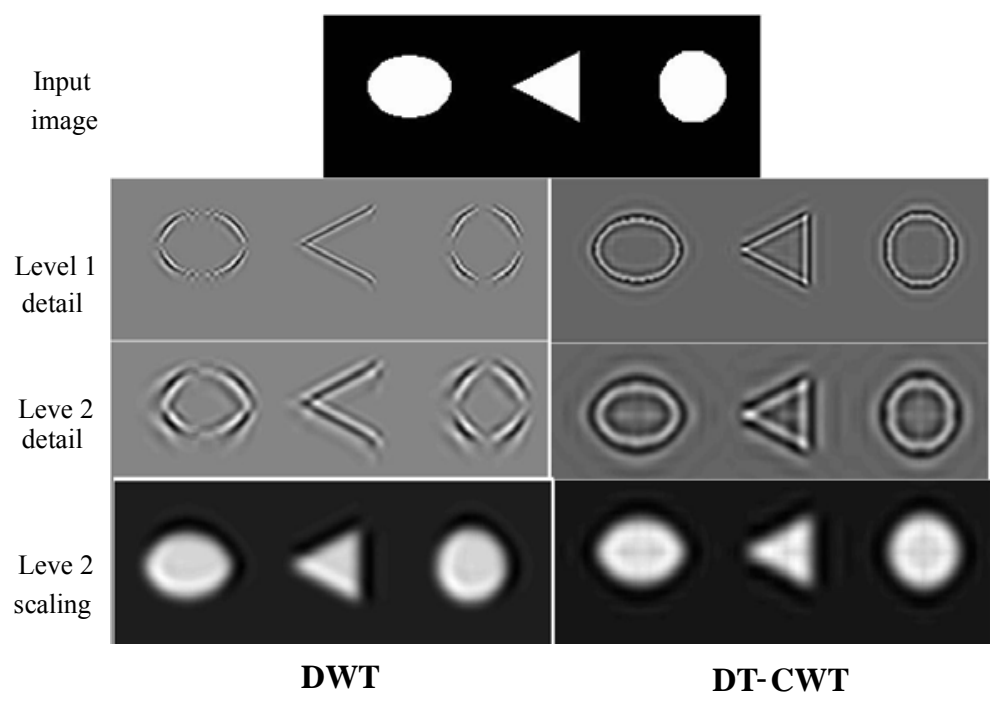

Fig. 4 Components of reconstructed image using DWT (left column) and DT-CWT (right column)

Figure 4 shows the components of reconstructed image using DWT and DT-CWT, which include detail and scaling image at levels 1 to 2. A comparison is made in the left and right column, the DWT and DT-CWT can partly identify the location and shape of the edge. However, the result generated using the DT-CWT preserves a very good consistency along the edge of the input image, which does not lose edge information. Therefore, the DT-CWT has an obvious advantage in an accurate assessment of morphological features, such as pits, protuberances and grooves.

\subsubsection{Determination of filtering process}

To effectively distinguish roughness and defect information during the extracting of surface roughness of $\mathrm{Al} / \mathrm{SiCp}$ composites, two filtering processes can be realized: (1) Filter out the defect information after extracting the surface roughness; (2) Extract surface roughness after filtering out defect information. Figure 5 (a) and (b) show the distortion 
values at the defect edge for the two roughness extraction methods. It can be seen from the figures that the filtering process of extracting the surface roughness after filtering the defect information can reduce the dot-distortion near the defect area effectively. Obviously, the more accurate roughness reference plane and roughness surface can be obtained by using method 2 . Therefore, the second filtering process is adopted to conduct the extraction of surface roughness in machining $\mathrm{Al} / \mathrm{SiCp}$ composites.
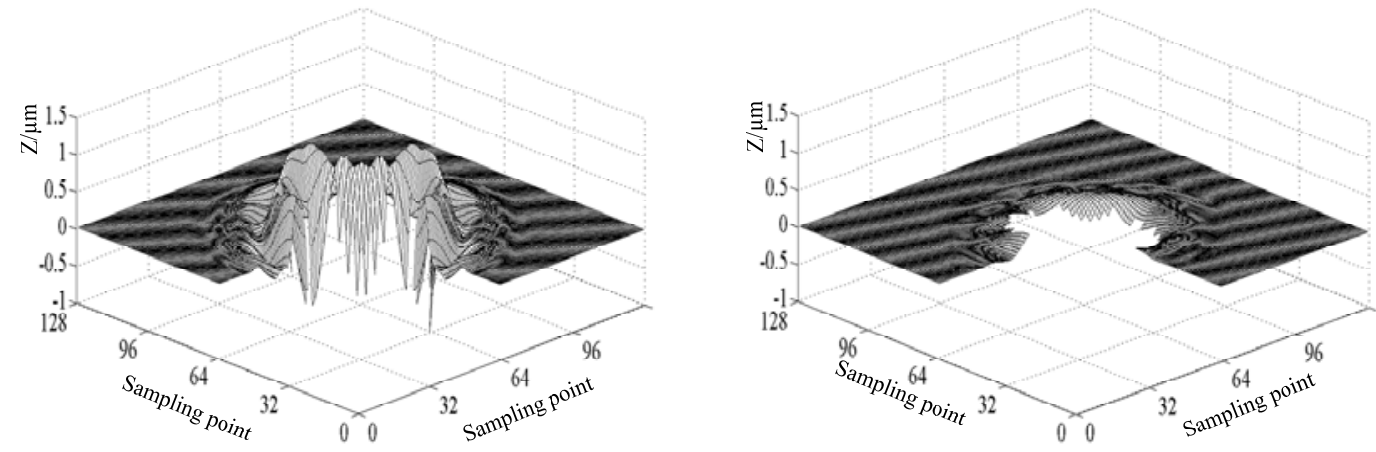

(a)The distortion in outliers using the method 1 (b)The distortion in outliers using the method 2

Fig. 5 Comparison of distortion in outliers between two filtering methods

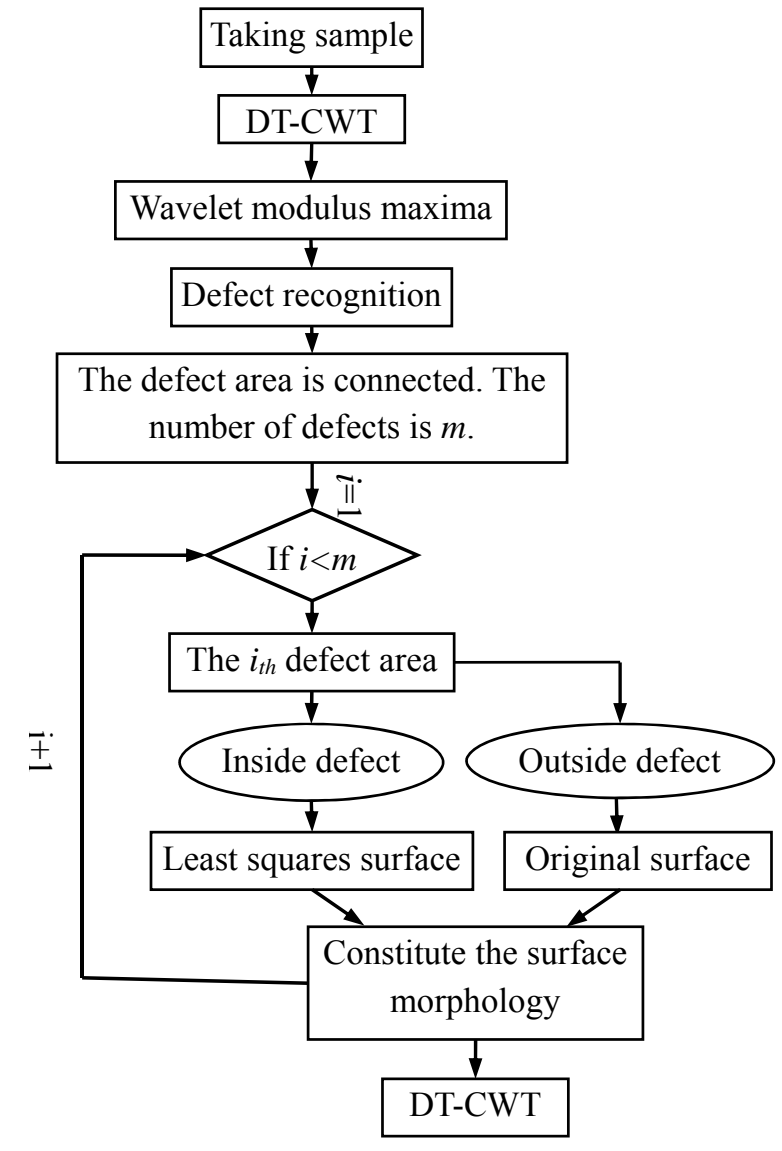

Fig. 6 Flow chart of the roughness extraction method

Figure 6 shows flow chart of the roughness extraction method based on the second filtering process. The DT-CWT is adopted to decompose the extracting surface information of $\mathrm{Al} / \mathrm{SiCp}$ composites. Then wavelet moduli are calculated by the detail sections of 6-direction. The wavelet modulus maxima is used to identify defects, and the defect area is characterized by binary image (Jiang and Blunt, 2004). The area of the binary image is calibrated and dialed respectively. The edge of a connected area is extracted, and the corresponding three-dimensional surface information is subjected to construct the least squares surface. Then the least squares surface takes the place of the defective area. The boundary of 
defects is replaced by the weighted average of the least square surface and height information in the machined surface of $\mathrm{Al} / \mathrm{SiCp}$ composites. The surface morphology of $\mathrm{Al} / \mathrm{SiCp}$ composites is reconstructed by processing all the connected regions. The frequency band-energy method is adopted to determine the decomposition level of DT-CWT in the surface morphology (Zhang et al., 2011). Finally, the layer scale information is reconstructed to obtain roughness reference plane and then roughness surface information is structured.

\subsubsection{Validation of roughness extraction method}

To verify the reliability of the roughness extraction method based on DT-CWT, the harmonic signal is adopted to construct the information of surface roughness, and the surface roughness informations of two-dimensional(2D) and three-dimensional(3D) are extracted respectively.

The constructing 2D signal is shown in Fig. 7 (a), and 2D surface roughness is extracted by using the roughness extraction method based on DT-CWT. Figure 7 (b) shows the location of the extracted defects. It can be seen from the figure that DT-CWT can accurately extract the 2D defects location. The straight-line segment formed by the two points at the edge of defects is used to replace the defects information. After filtering by DT-CWT, the roughness Ra is 0.3813 . The deviation is $0.58 \%$ compared to the roughness value extracted from the $2 \mathrm{D}$ signal with no defect by DT-CWT that is 0.3791 . Figure 8 shows the binary image, which includes the extracted defects boundary and the actual location of defects. The white area is the defects location and white border is the extracted defects boundary. Comparing white areas with white borders, it can be found that the edge information of the extracted defects is accurate.

The 3D signal is constructed shown in Fig. 9 (a). The reference surface determined by least square method is adopted to replace the defective area. The surface information at the boundary is replaced by the weighted average. Then the roughness reference surface and roughness surface shown in Fig. 9 (b) and Fig. 9 (c) is obtained by DT-CWT. The surface roughness value obtained by filtering is 0.4073 . The deviation is about $0.025 \%$ compared to the roughness value extracted from the 3D surface with no defect by DT-CWT that is 0.4072 . Therefore, the roughness extraction method based on DTCWT can separate the roughness information and the defect information accurately and get the exact roughness value.

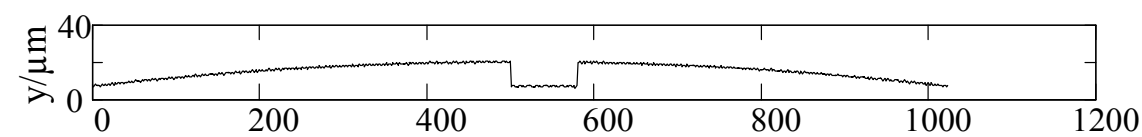

(a)

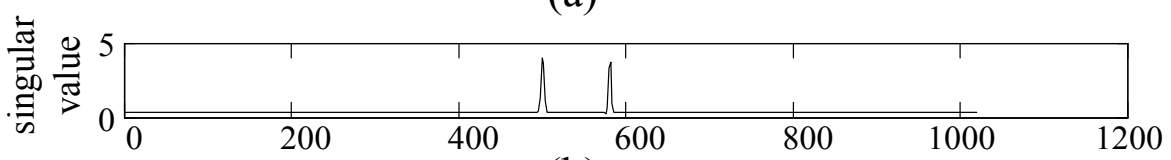

(b)

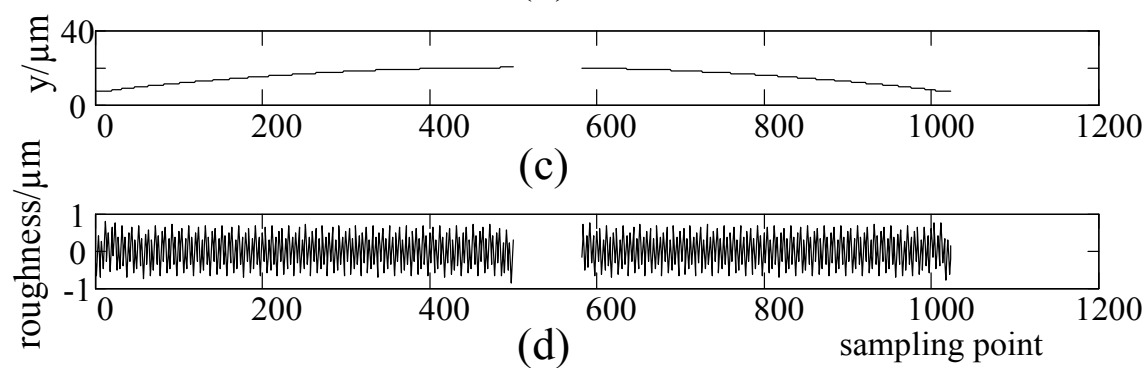

Fig. 7 The 2D surface roughness by the roughness extraction method based on DT-CWT. (a) Original surface. (b) Defect location. (c) Baseline of roughness. (d) Roughness 


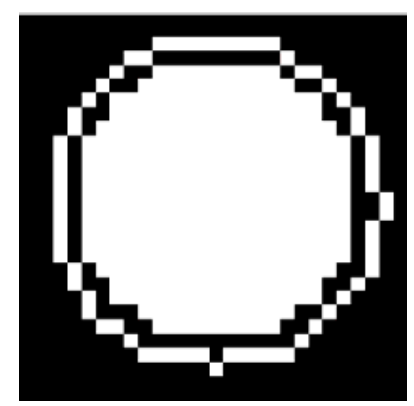

Fig. 8 Extracted defects boundary and actual location of defects

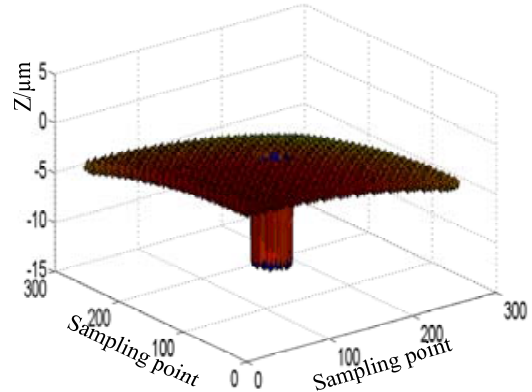

(a) Initial surface

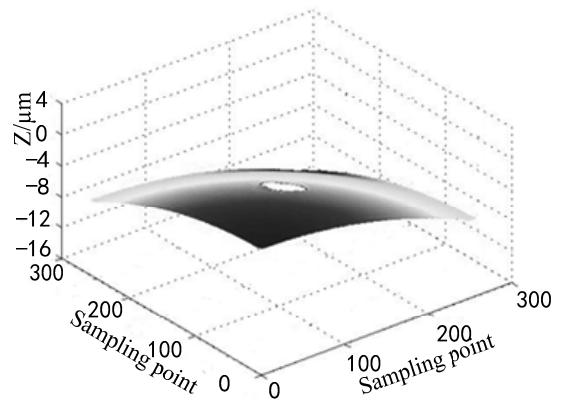

(b) Reference surface

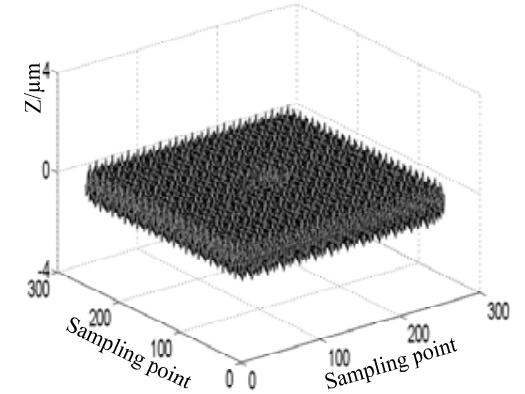

(c) Roughness surface

Fig. 9 The 3D roughness surface by the roughness extraction method based on DT-CWT

\subsubsection{Comparison between different surface roughness extraction methods}

To compare the effects of different surface roughness extraction methods on the extracted defects, the surface roughness information of the 3D surface with void defects is extracted by the least squares method, the Gaussian filter method and the roughness extraction method based on DT-CWT. MATLAB software is adopted to compile the calculation programs for three roughness information extraction methods. The reference surface and the roughness surface are obtained by three roughness information extraction methods respectively. The results are shown in Fig. 9 , Fig. 10 and Fig. 11.

As it can be seen from Fig. 10, the machined surface shape size and machining defects are completely included in the roughness when the roughness information is extracted by the least squares method. The least squares method is adopted to extract the roughness resulting in the calculated value of roughness being $1.6655 \mu \mathrm{m}$, which is significantly larger than the theoretical value of $0.4112 \mu \mathrm{m}$. In Fig. 11, it is found that the reference surface gotten by Gaussian filter has serious distortions near the singular point, resulting in generating the surface roughness error. However, the roughness extraction method based on DT-CWT not only can distinguish between surface defects and roughness but also can effectively reduce the distortion of Gaussian near the singular point, and get the accurate value of roughness, as shown in Fig. 9.

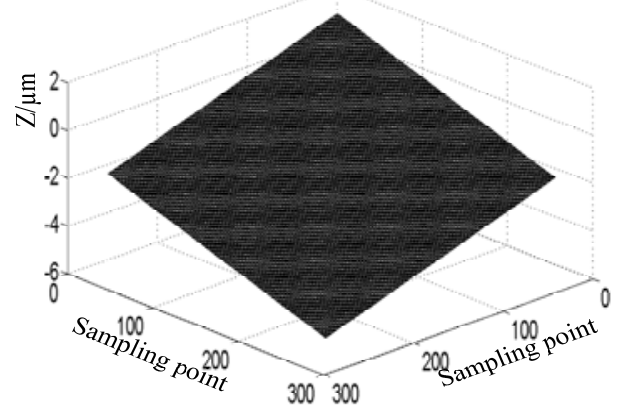

(a) Reference surface

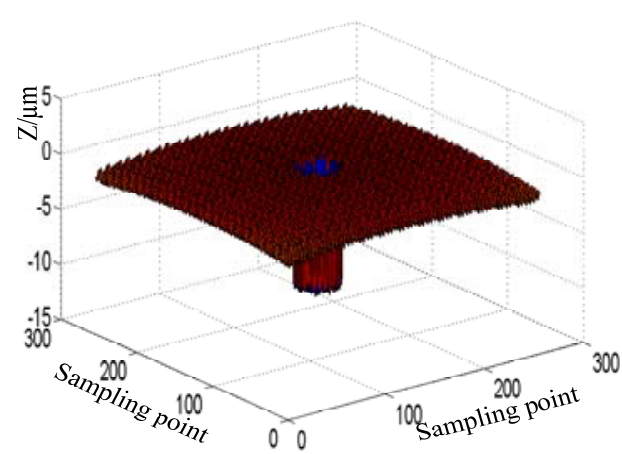

(b) Roughness surface

Fig. 10 The 3D roughness surface by the least square method 


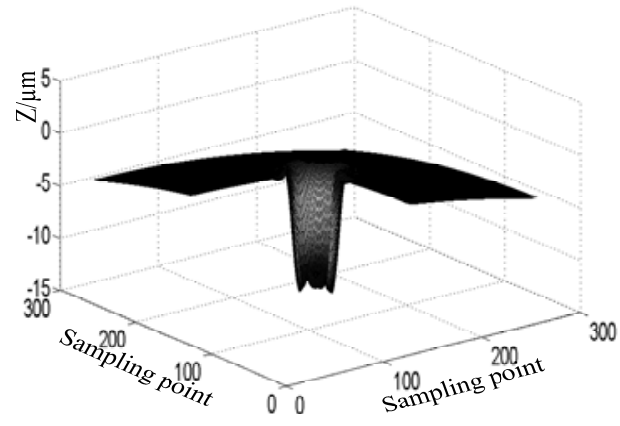

(a) Reference surface

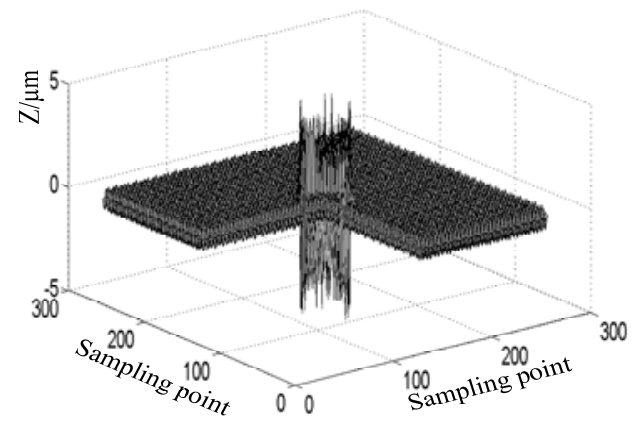

(b) Roughness surface

Fig. 11 The 3D roughness surface by Gaussian filter

\subsubsection{Measured data analysis}

Table 4 Roughness value of different roughness extraction methods

\begin{tabular}{c|c|c|c|c}
\hline \hline Roughness extraction method & $\mathrm{a}$ & $\mathrm{b}$ & $\mathrm{c}$ & $\mathrm{d}$ \\
\hline Least square method & 3.682 & 1.689 & 1.747 & 2.437 \\
Gaussian filter method & 2.732 & 1.662 & 1.731 & 2.023 \\
Roughness extraction method based on DT-CWT & 1.533 & 1.418 & 1.447 & 1.503 \\
\hline
\end{tabular}

To verify the advantages of the roughness extraction method based on DT-CWT, the 6063Al matrix composite was machined at a feed of $0.1 \mathrm{~mm} / \mathrm{rev}$ and cutting speed of $120 \mathrm{~m} / \mathrm{min}$. The roughness of the obtained machined surface was measured and extracted. Considering that the size of SiC particle is $15 \mu \mathrm{m}$ and the size of voids is about three times of the particle size, so the sampling length is set at $3 \mu \mathrm{m}$ to more efficient and complete identification of defect information. The roughness at four points $(a, b, c, d)$ in the same surface is extracted and calculated by the least squares method, the Gaussian filter method and the roughness extraction method based on DT-CWT. The measured values are given in Table 4.It can be seen from the table that the measured values of roughness at four points by least squares method and Gaussian filter have a larger deviation. However, the distribution of roughness gotten by the roughness extraction method based on DT-CWT is more average. Because the machined surfaces of $6063 \mathrm{Al} / \mathrm{SiCp}$ composites have large numbers of defects such as large voids and bumps, and the distribution of defects is random and uneven. The least squares method includes defects in surface roughness completely. The Gaussian filter method can filter out defect information in some degree. But, the distortion values near the singular points when big defects exist at the machined surface result in an increase in the extracted surface roughness value. The roughness extraction method based on DT-CWT uses the double-tree complex wavelet transform with similar translation invariance and good 6-direction recognition to identify the defects (Kingsbury, 2001), which can separate the surface defects and roughness completely. Obviously, the roughness extraction method based on DT-CWT has significant advantages and is suitable for the evaluation of surface quality in machining Al/SiCp composites.

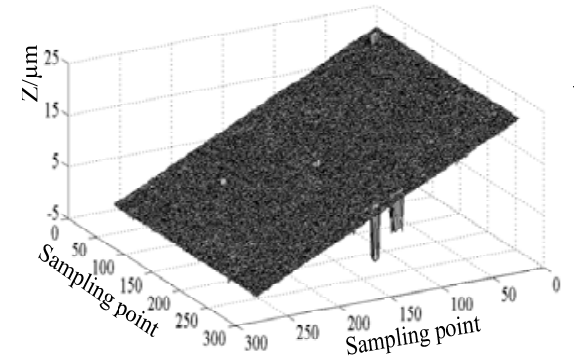

(a)Initial surface

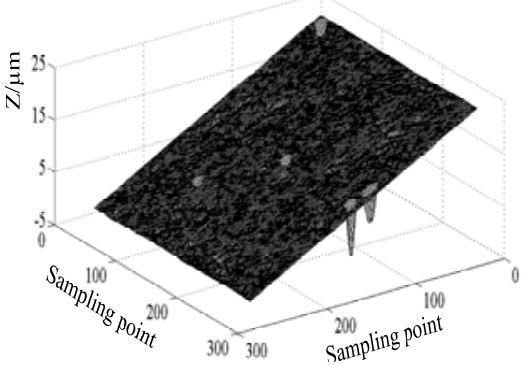

(b)Reference surface

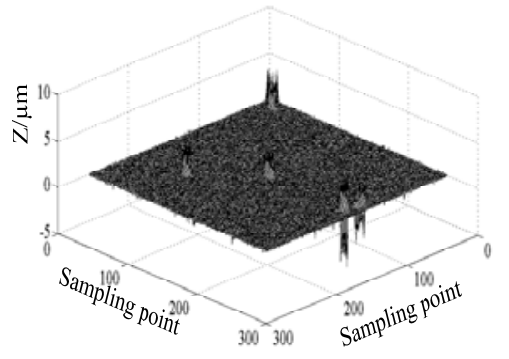

(c)Roughness surface 
Fig. 12 Measured data by DT-CWT filter

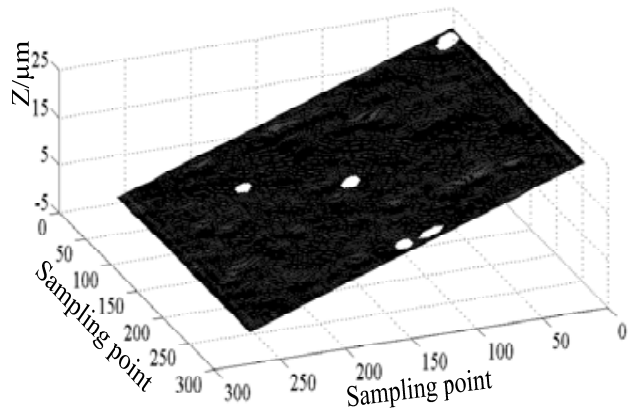

(a) Reference surface

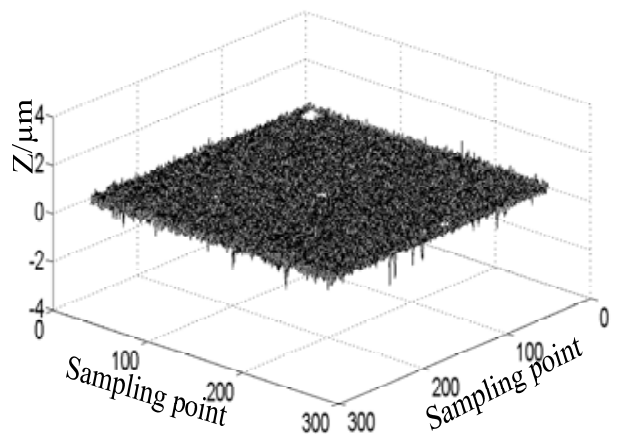

(b) Roughness surface

Fig. 13 Measured data by the roughness extraction method based on DT-CWT

Figure 12 (a) presents the initial surface of $6063 \mathrm{Al} / \mathrm{SiCp}$ composites after polishing finding that the surface morphology is complex, and the defects are randomly and irregular in shape. The DT-CWT filter is adopted to construct the reference plane and roughness plane directly, as shown in Fig. 12 (b) and (c). It can be found from the figure that this filter method has the distortion near the defects edge, which results in that the extracted surface roughness value is larger than the actual roughness value. Figure 13 (a) and (b) is the reference plane and roughness plane constructed by the second filtering process based on DT-CWT, which can significantly reduce the distortion value. Thus, the roughness extraction method based on DT-CWT is more suitable for extracting the roughness of Al/SiCp composites.

\subsection{Evaluation of surface roughness of $\mathrm{Al} / \mathrm{SiC}$ composites}

The roughness extraction method based on DT-CWT is used to evaluate the surface roughness of Al/SiCp composites with different aluminum matrix, as shown in Fig. 14. It can be seen from the figure that the cutting speed has little effect on extracting roughness value (ERV) of $\mathrm{Al} / \mathrm{SiCp}$ composites with high volume particles fraction. It is due to the fact that the network structure constituted by the connection between particles and particles bears cutting force. And, the machining $\mathrm{Al} / \mathrm{SiCp}$ composites presents brittle removal mechanism basically. Therefore, the friction coefficient between the chip and the rake face is approximately constant value and the average cutting force cannot obviously change with increasing the cutting speed (Dabade et al., 2009). In addition, it can be seen from Fig. 14 that the roughness value of $6063 \mathrm{Al} / \mathrm{SiCp}$ composite is significantly higher than that of $2024 \mathrm{Al} / \mathrm{SiCp}$ composite. The fluctuation frequency of cutting force in machining 2024Al/SiCp composites is lower than that of $6063 \mathrm{Al} / \mathrm{SiCp}$ composites because the hardness of 2024Al matrix is higher than that of 6063Al matrix. The violent fluctuation of the cutting force reduces the machined surface quality, which increases surface roughness value (Khdir, 2007). Moreover, the 6063Al is more sensitive to temperature compared with 2024Al, which leads to larger areas of plastic side flow generated on the machined surface of $6063 \mathrm{Al} / \mathrm{SiCp}$ composites. The increase in plastic side flow area induced by thermal softening of $\mathrm{Al}$ matrix increases the surface roughness in machining $\mathrm{Al} / \mathrm{SiCp}$ composites. According to the description above, it is found that the surface roughness value of $2024 \mathrm{Al}$ matrix composites is lower than that of $6063 \mathrm{Al}$ composites when machining $\mathrm{Al} / \mathrm{SiCp}$ composites. The roughness extraction method based on DT-CWT can be applied not only to the surface quality evaluation of $\mathrm{Al} / \mathrm{SiCp}$ composites, but also have some guidance on the evaluation of the machined surface with many defects. In the future work, more engineering surface quality evaluation will be carried out to demonstrate the application of using the proposed roughness extraction method in the assessment of machined surface. 


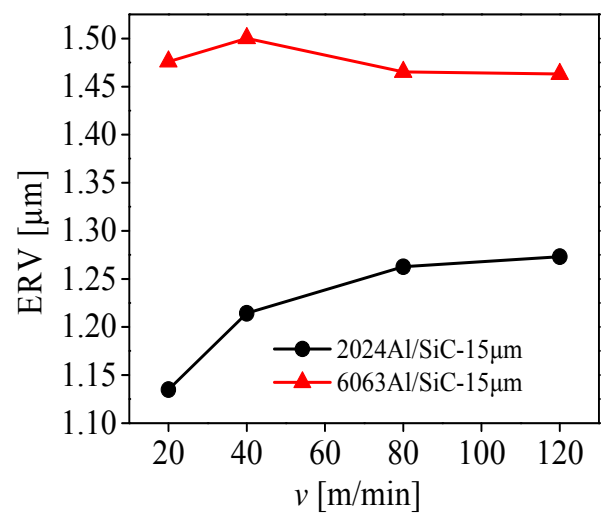

Fig. 14 The extracting roughness value in machining $\mathrm{Al} / \mathrm{SiCp}$ composites (feed rate $f=0.1 \mathrm{~mm} / \mathrm{rev}$ )

\section{Conclusions}

This paper presents the formation mechanism of surface defects in machining $\mathrm{Al} / \mathrm{SiCp}$ composites. In order to extract the surface defects from roughness and evaluate the surface roughness of $\mathrm{Al} / \mathrm{SiCp}$ composites, a roughness extraction method based on DT-CWT is proposed. The following conclusions can be drawn:

(1) There are lots of defects such as grooves, pits, protuberances and voids on the machined surface of $\mathrm{Al} / \mathrm{SiCp}$ composites. The crushed or debonded particles pressed by the flank face undergo a certain length of tillage in the direction of cutting speed, forming some plough grooves on the softer aluminum matrix. The pits are caused by the particles stripping on the machined surface of $\mathrm{Al} / \mathrm{SiCp}$ composites. There is a certain degree of springback due to the ironing effect of secondary flank face on the surface, forming micro protuberances on the machined surface. The micro voids are formed either due to fine $\mathrm{SiC}$ particles detached from the matrix or due to the rotation of the $\mathrm{SiC}$ particles in the $\mathrm{Al}$ matrix. The crushed particles can either be pressed in $\mathrm{Al}$ matrix bringing about big bumps or be pulled out of the machined surface causing large pits.

(2) The roughness extraction method based on DT-CWT can get accurate reference plane and the exact roughness value. Compared with the least squares method and the Gaussian filter method, the roughness extraction method based on DT-CWT has high stability and can distinguish between the surface roughness and defect information effectively. Therefore, the roughness extraction method based on DT-CWT is more suitable for the extraction of surface roughness in machining $\mathrm{Al} / \mathrm{SiCp}$ composites. Then, this method is adopted to evaluate the surface roughness of $\mathrm{Al} / \mathrm{SiCp}$ composites. The result shows that the surface roughness value of $2024 \mathrm{Al}$ matrix composite is lower than that of $6063 \mathrm{Al}$ matrix composite.

\section{Acknowledgments}

This work was supported by the National Nature Science Foundation of China [grant number 51775083].

\section{References}

Charpentier, P. L., Stone, B. C., Ernst, S. C. and Thomas, J. F., Characterization and modeling of the high temperature flow behavior of aluminum alloy 2024, Metallurgical Transactions A, Vol.17, No.12 (1986), pp.2227-2237.

Dabade, U. A., Dapkekar, D. and Joshi, S. S., Modeling of chip-tool interface friction to predict cutting forces in machining of $\mathrm{Al} / \mathrm{SiCp}$ composites, International Journal of Machine Tools \& Manufacture, Vol.49, No.9 (2009), pp.690-700.

Dabade, U. A., Joshi, S. S., Balasubramaniam, R. and Bhanuprasad, V. V., Surface finish and integrity of machined surfaces on al/sicp composites, Journal of Materials Processing Technology, s Vol.192-193, No.1 (2007), pp.166174.

Davim, J. P., Machining of Metal Matrix Composites (2012). Springer London.

El-Gallab, M. and Sklad, M., Machining of $\mathrm{Al} / \mathrm{SiC}$ particulate metal matrix composites: Part II: Workpiece surface integrity, Journal of Materials Processing Technology, Vol.83, No.1-3 (1998), pp.277-285.

Ge, Y. F., Xu, J. H., Yang, H., Luo, S. B. and Fu, Y. C., Workpiece surface quality when ultra-precision turning of sicp /al composites, Journal of Materials Processing Technology, Vol.203, No.1-3 (2008), pp.166-175. 
Jiang, X. and Blunt, L., Third generation wavelet for the extraction of morphological features from micro and nano scalar surfaces, Wear, Vol.257, No.12 (2004), pp.1235-1240.

Kannan, S. and Kishawy, H. A., Surface characteristics of machined aluminium metal matrix composites, International Journal of Machine Tools \& Manufacture, Vol.46, No.15 (2006), pp.2017-2025.

Kannan, S., Kishawy, H. A. and Deiab, I., Cutting forces and TEM analysis of the generated surface during machining metal matrix composites, Journal of Materials Processing Technology, Vol.209, No.5 (2009), pp.2260-2269.

Khan, A. S., Variable strain rate sensitivity in an aluminum alloy: Response and constitutive modeling, International Journal of Plasticity, Vol.36, No.9 (2012), pp.1-14.

Khdir, Y. K., The effect of cutting tool vibration on surface roughness of workpiece in dry turning operation, Engineering \& Technology, Vol.20, No.7 (2007), pp.879-889.

Kingsbury, N., A dual-tree complex wavelet transform with improved orthogonality and symmetry properties, International Conference on Image Processing (2000), Proceedings IEEE, Vol.2, pp.375-378.

Kingsbury, N., Complex wavelets for shift invariant analysis and filtering of signals, Applied \& Computational Harmonic Analysis, Vol.10, No.3 (2001), pp.234-253.

Kingsbury, N., The dual-tree complex wavelet transform: A new efficient tool for image restoration and enhancement, Signal Processing Conference (2015), IEEE, pp.1-4.

Kunze, J. M. and Bampton, C. C., Challenges to developing and producing MMCs for space applications, JOM, Vol.53, No.4 (2001), pp.22-25.

Palanikumar, K. and Karthikeyan, R., Assessment of factors influencing surface roughness on the machining of al/sic particulate composites, Materials \& Design, Vol.28, No.5 (1998), pp.1584-1591.

Pramanik, A., Zhang, L. C. and Arsecularatne, J. A., Machining of metal matrix composites: effect of ceramic particles on residual stress, surface roughness and chip formation. International Journal of Machine Tools \& Manufacture, Vol.48, No.15 (2008), pp.1613-1625.

Qiu, M., Delic, A. and Raeymaekers, B., The Effect of Texture Shape on the Load-Carrying Capacity of Gas-Lubricated Parallel Slider Bearings, Tribology Letters, Vol.48, No.3 (2012), pp.315-327.

Qiu, M., Minson, B. R. and Raeymaekers, B., The effect of texture shape on the friction coefficient and stiffness of gaslubricated parallel slider bearings, Tribology International, Vol.67, No.4 (2013), pp.278-288.

Rawal, S. P., Metal-matrix composites for space applications, JOM, Vol.53, No.4 (2001), pp.14-17.

Rohatgi, P., Cast aluminum-matrix composites for automotive applications, JOM, Vol.43, No.4 (1991), pp.10-15.

Svahn, F., Åsa Kassman-Rudolphi. and Wallén, E., The influence of surface roughness on friction and wear of machine element coatings, Wear, Vol.254, No.11 (2003), pp.1092-1098.

Wang, Y. J., Zhou, M. and Zhang, Y. J., Study on Choice of Reference Planes for 3D Machined Surface Roughness of SiCp/Al Composites during High Speed Milling Process, Advanced Materials Research, No.150-151 (2011), pp.129-132.

Zhang, G., Liu, X. and Lu, W., Comprehensive evaluation of surface topography in running-in wear process, International Symposium on Precision Mechanical Measurements (2013), International Society for Optics and Photonics.

Zhang, Z. H., Guo, L. B., Cui, H. and Zhang, B., Surface Texture Evaluation of Micro-WEDM, Applied Mechanics \& Materials, No.138-139 (2011), pp.1251-1257.

Zhou, P. and Zhao, F., 3D evaluation method of cutting surface topography of carbon / phenolic (C/Ph) composite, Journal of Wuhan University of Technology, Vol.26, No.3 (2011), pp.459-463 